\title{
Desafios e potencialidades da escrita na formação docente em matemática*
}

\author{
Maria Teresa Menezes Freitas \\ Universidade Federal de Uberlândia, Faculdade de Matemática
}

\section{Dario Fiorentini}

Universidade Estadual de Campinas, Faculdade de Educação, Programa de Pós-Graduação em Educação

\section{Introdução}

Este artigo relata parte de uma pesquisa de doutorado (Freitas, 2006) ${ }^{1}$ que teve como objeto de estudo o processo de formação de professores ocorrido a partir da disciplina Geometria Plana e Desenho Geométrico (GPDG), ministrada na licenciatura em matemática da Universidade Estadual de Campinas (UNICAMP). Essa disciplina diferenciou-se por fazer uso de diferentes recursos comunicativos, em especial da escrita discursiva, tendo por objetivo proporcionar uma formação conceitual voltada às necessidades da prática docente no ensino fundamental.

A investigação foi organizada a partir da seguinte hipótese de trabalho: a escrita discursiva e reflexiva - isto é, não estritamente simbólica ou formal -

* Texto apresentado no Grupo de Trabalho Educação Matemática, na 29a Reunião Anual da Associação Nacional de PósGraduação e Pesquisa em Educação (ANPEd), realizada em Caxambu (MG), de 15 a 18 de outubro de 2006.

${ }^{1}$ Desenvolvida na Faculdade de Educação da Universidade Estadual de Campinas (UNICAMP) pela primeira autora, tendo como orientador o segundo autor deste artigo. pode potencializar o desenvolvimento profissional do professor de matemática. A imersão nesse ambiente de formação docente trouxe vestígios para responder às seguintes questões de investigação: que contribuições a inserção de diferentes formas de comunicação - especialmente a escrita - em uma disciplina de conteúdo específico (geometria) traz à formação e ao desenvolvimento profissional do professor de matemática? Como acontece, nesse processo, a constituição da identidade profissional?

Neste texto, apresentamos, inicialmente, uma breve discussão teórica, pela perspectiva histórico-cultural, sobre o papel e o lugar da escrita na formação docente. A seguir, trazemos alguns detalhes relativos ao processo metodológico da pesquisa narrativa. Em continuidade, apresentamos a narrativa de formação de um dos protagonistas que participou da referida disciplina; finalmente, algumas conclusões relativas à importância da escrita discursiva e reflexiva na formação docente.

\section{A escrita na formação docente}

O potencial formativo da escrita discursiva vem sendo, há algum tempo, destacado e investigado jun- 
to às disciplinas didático-pedagógicas, sobretudo quando se realiza pesquisa sobre estagiários, utilizando e explorando registros de campo (Freitas, 2000). Para Bogdan e Biklen (1994, p. 150), essas notas constituem-se não apenas em "relato escrito daquilo que o investigador ouve, vê, experiencia e pensa no decurso da recolha e refletindo sobre os dados de um estudo qualitativo", mas também oferecem elementos para a auto-reflexão do formando e do formador; permitem, além disso, a intervenção problematizadora do formador sobre as concepções, crenças e saberes dos futuros professores sobre a matemática e seu processo de ensino e aprendizagem.

Se, de um lado, em Freitas (2000) evidencia-se o potencial formativo da escrita, de outro, verificamos que os futuros professores de matemática apresentam dificuldade em colocar no papel suas reflexões e seus pensamentos, o que leva a supor que os cursos de graduação em matemática pouco enfatizam e exploram as interações mediadas pela escrita discursiva.

Os primeiros depoimentos obtidos dos licenciandos participantes do presente estudo sinalizavam a confirmação de tal conjectura:

[...] a gente não tem este costume aqui na Faculdade. $\mathrm{O}$ pessoal que tem é de fora [pausa] trouxe de fora e pelo menos neste curso não tem, a gente não escreve muito. (FS, E jun. 2003) $)^{2}$

[...] há uma certa cultura que existe dentro da faculdade de Matemática de que a nossa linguagem, para quem pretende fazer Matemática, tem que ser totalmente formalizada... (FF, E jul. 2003) $)^{3}$

Esses depoimentos parecem indicar que a dificuldade dos alunos em estabelecer uma comunicação escrita compreensiva, durante a licenciatura, pode ser

${ }^{2}$ Trecho de entrevista concedida por FS, licenciando em matemática da UNICAMP, em junho de 2003.

${ }^{3}$ Trecho de entrevista concedida por FF, licenciando em matemática da UNICAMP, em julho de 2003. conseqüência de uma prática que prioriza a escrita técnica e formal em detrimento da escrita reflexiva, discursiva e narrativa sobre aquilo que se aprende e se ensina.

Em relação à leitura e à escrita de estudantes universitários, Britto (2003) argumenta que as dificuldades "não advêm da falta de uma capacidade genérica da redação ou mesmo de leitura, mas sim do modo como estes estudantes interagem e convivem com os objetos da cultura letrada, em particular com as formas de produção do conhecimento formal" (p. 176).

Esse quadro problemático reforça o nosso propósito de investigar o que e como acontece, durante a formação do futuro professor, quando nas disciplinas de matemática se passa também a privilegiar um processo de escrita reflexiva.

Saber argumentar, dialogar e comunicar, de maneira clara e compreensível, por via oral, escrita e videográfica, ${ }^{4}$ são competências que vêm adquirindo cada vez mais importância na formação profissional dos futuros professores. Essas diferentes formas de comunicação complementam-se, e é imprescindível, sobretudo no contexto atual da sociedade do conhecimento e da informação, a sua utilização articulada.

Os cursos de formação matemática do professor, entretanto, continuam a desenvolver uma prática de ensino em que se destaca a oralidade como forma de comunicação. Essa linguagem, de um lado, pode ajudar na sistematização lógica do conhecimento matemático, mas, de outro, pouco contribui para a exploração e problematização dos conceitos que estão sendo ensinados e aprendidos. A licenciatura em matemática, conforme o depoimento de um licenciando da UNICAMP, continua ainda sendo marcada por uma tradição de pouca leitura e pouca escrita, priorizando um tipo de linguagem que, por ser técnica, inibe aquele que escreve, impedindo, assim, que exponha suas idéias com maior flexibilidade e crítica:

${ }^{4}$ Por videográfica entende-se a comunicação mediada preponderantemente pela imagem (figuras, vídeo, construções dinâmicas apresentadas na tela do computador). 
[...] talvez a falta de costume de escrever, mesmo. A gente escreve muito pouco por causa do curso, nas disciplinas de Matemática são pouquíssimas as vezes que a gente escreve... A escrita ajuda muito na hora de traduzir esse pensamento técnico que valoriza muito mais a interpretação. Muitas vezes eu escrevendo e tal, eu percebi coisas que eu não teria percebido se eu tivesse só feito uma demonstração só com símbolos... (FP, E jul. 2003)5

Identificamos, assim, nos cursos de formação de professores de matemática, a carência de uma escrita discursiva, compreensiva e interpretativa - aquela que não procura apenas perceber logicamente o que se escreve, mas também busca explorar os múltiplos significados das idéias matemáticas.

Nós, entretanto, evidenciamos a exploração intencional da leitura e da escrita, no processo de ensinar e aprender matemática na licenciatura, como uma forma potencial que amplia o poder de compreensão e reflexão dos futuros professores sobre a matemática como objeto de ensino e aprendizagem, assim promovendo a constituição pessoal e profissional do futuro professor de matemática. Essa, inclusive, é nossa hipótese investigativa de trabalho, a qual nos leva a delimitar como foco de estudo o papel da escrita discursiva/narrativa na formação docente em matemática.

Teoricamente, este estudo encontra apoio, primeiramente, nas idéias de Larrosa (2002), sobretudo em relação à sua concepção de educação a partir do par "experiência e sentido". Segundo ele, "as palavras produzem sentido, criam realidades e, às vezes, funcionam como potentes mecanismos de subjetivação" (p. 2).

Outros autores também associam experiência com aprendizagem. Essa associação, entretanto, estabelece um vínculo profundo com a capacidade de reflexão do homem sobre a experiência, para que ela assuma um caráter não passageiro, mas comprometido.

${ }^{5}$ Trecho de entrevista concedida por FP, licenciando em Matemática da UNICAMP, em julho/2003.
Kramer (2000), por exemplo, distingue vivência (reação a choques) de experiência (vivido que é pensado, narrado):

$$
\begin{aligned}
& \text { [...] na vivência, a ação se esgota no momento de sua reali- } \\
& \text { zação (por isso é finita); na experiência, a ação é contada a } \\
& \text { um outro, lida pelo outro, compartilhada, se tornando infi- } \\
& \text { nita. Esse caráter de permanência, de ir além do tempo vi- } \\
& \text { vido e de ser coletiva, constitui a experiência. (p. 113) }
\end{aligned}
$$

Para Bruner (1997), há dois modos cognitivos diferentes de ordenar a experiência e construir a realidade: a "história" e o "argumento". O primeiro refere-se à forma discursiva ou narrativa de expressão, e o segundo, à comunicação por meio de símbolos e procedimentos formais ou lógico-matemáticos. Cada um desses modos desempenha um papel importante na atribuição de significados para a experiência. Entretanto, "esforços para reduzir um modo ao outro ou para ignorar um à custa do outro inevitavelmente deixam de captar a rica diversidade do pensamento" (p. 11).

Para Powell (2001) e Powell e Bairral (2006), a reflexão sobre as experiências matemáticas, mediada pela escrita, pode levar os alunos a pensarem criticamente sobre suas próprias idéias, desenvolvendo a cognição matemática e desencadeando também processos metacognitivos.

Oliveira (1995, p. 154) complementa destacando que a escrita favorece a construção da consciência metalingüística, pois, pela escrita, “o sujeito pode refletir e construir conhecimento explícito e a consciência metacognitiva, pela possibilidade de verificação do discurso escrito enquanto produto de pensamento, de objetivação da experiência pessoal".

Essa consciência metalingüística e metacognitiva em constituição é percebida na seguinte reflexão de um dos participantes de nossa pesquisa:

\footnotetext{
[...] revisar me fazia pensar se o que eu estava escrevendo

fazia sentido, se a idéia geral estava boa e me fazia pensar de novo. Sempre, ao rever, eu encontrava - foram raras as vezes que eu não encontrei - coisas que eu poderia acrescentar ou alguma coisa que eu poderia retirar ou alguma
} 
coisa que eu poderia reescrever deixando mais claro e muitas coisas que eu entendia melhor quando eu estava relendo [...]; me fazia entender muitas vezes coisas que, talvez, não estivessem muito claras para mim ou que estavam claras, mas eu interpretava de uma outra maneira mais interessante ou chegava a outras possibilidades para a mesma coisa. (FP, E jul. 2003)

Compartilhamos com Larrosa (2002) a idéia de que "as palavras determinam nosso pensamento porque não pensamos com pensamentos, mas com palavras" (p. 2). Pensar é, sobretudo, dar sentido ao que somos e fazemos e ao que nos acontece. Mas, a possibilidade de que algo nos aconteça ou nos toque como experiência formativa requer

[...] parar para pensar, parar para olhar, parar para escutar, pensar mais devagar, olhar mais devagar, e escutar mais devagar; parar para sentir, sentir mais devagar, demorar-se nos detalhes, suspender a opinião, suspender o juízo, suspender a vontade, suspender o automatismo da ação, cultivar a atenção e a delicadeza, abrir os olhos e os ouvidos, falar sobre o que nos acontece, aprender a lentidão, escutar aos outros, cultivar a arte do encontro, calar muito, ter paciência e dar-se tempo e espaço. (p. 3)

Para esse autor, um dos componentes fundamentais da experiência é sua potencialidade formativa. A experiência é "aquilo que 'nos passa', ou que nos toca, ou que nos acontece, e ao passar-nos forma e nos transforma. Somente o sujeito da experiência está, portanto, aberto a sua própria transformação" (idem, p. 6).

O sentido de experiência, nessa perspectiva, ressalta a sensibilidade inerente a esses momentos que não são apenas vividos, mas que possuem a potencialidade de mobilizar idéias, crenças e valores que fazem com que o indivíduo se posicione e (re)signifique seu modo de agir e pensar, caracterizando assim o aspecto formador.

A concepção de formação, associada ao conceito de experiência dos autores que já mencionamos, parece pôr em xeque os processos de ensino de matemática que privilegiam apenas sua leitura e escrita técnica e formal. Para haver experiência autenticamente formativa, com base nessa concepção, o ensino da matemática teria que contemplar uma prática exploratória, comunicativa e intersubjetiva, privilegiando a produção de sentidos sobre o que se aprende e se ensina. O contexto experiencial de produção de idéias e sentidos pode tornar-se mais próximo daquele em que irá atuar posteriormente, seja na condição de professor escolar, seja na de professor de professores.

Kramer (2000, p. 115), além disso, destaca o processo de humanização que pode ser desencadeado pela mediação da leitura e da escrita:

\footnotetext{
[...] trabalhando com leitura, escrita e formação, o horizonte precisa ser humanização, resgate da experiência humana, conquista da capacidade de ler e escrever o mundo e a história coletiva, de expressar-se, criar, mudar, de reescrevêlo numa outra direção e com outro sentido.
}

A preocupação, nessa perspectiva, está em oferecer aos alunos a capacidade não apenas de resolver problemas, mas também de produzir e comunicar significados sobre a matemática enquanto linguagem, pensamento e instrumento sociocultural de comunicação, leitura e compreensão do mundo.

Consideramos que a oportunidade de se expressar de outras formas apresenta-se como um convite ao futuro professor para expor os significados e as diferentes versões do seu modo de compreender e fazer compreender a matemática, deixando vir à tona $\mathrm{o}$ seu pensar, com as características adquiridas ao longo de sua história. E, assim, o futuro professor de matemática, em convivência com as diversas formas de expressar pensamento e idéias por meio da linguagem tanto oral como escrita, simbólica, tecnológica e pictórica, ao longo de sua formação, poderá perceber que "aquele que usa a língua não é o primeiro falante que rompeu pela primeira vez o eterno silêncio de um mundo mudo. Ele pode contar não apenas com o sistema da língua que utiliza, mas também a existência dos enunciados anteriores" (Bakhtin, 1986, p. 69).

A escrita, nessa perspectiva, não teria o papel de conformar o futuro profissional a modelos já estabe- 
lecidos, mas, ao contrário, traria à formação a possibilidade de criação e a multiplicidade de visões e diálogos que possam abrir caminhos para a atuação do profissional num mundo cada vez mais dinâmico e efêmero.

Tendo em vista a possibilidade de contribuição da escrita no contexto de formação, colocamo-nos na posição de investigadores curiosos e instigados a compreender as potencialidades formativas da utilização de modos diversos de comunicação, em especial a escrita, em um curso de licenciatura de matemática.

\section{Caminho investigativo - procedimentos metodológicos}

Para descrever e interpretar as contribuições da escrita na formação do futuro professor, não bastava observar e analisar o que aconteceu nas aulas de geometria. Era necessário também buscar indícios das repercussões dessa experiência nos anos seguintes, sobretudo quando o professor iniciasse a prática docente nas escolas. Isso implicava uma forte interlocução entre pesquisador e participantes, a fim de ter acesso aos sentimentos, pensamentos, perspectivas de cada um sobre o mundo, a experiência vivida e o ensino de matemática e, sobretudo, às suas próprias percepções sobre o processo de vir a ser professor, tendo como mediação a escrita. Encontramos aportes teórico-metodológicos para esse modo de pesquisar na pesquisa narrativa de Clandinin e Connelly (2000).

Na pesquisa narrativa, o participante da pesquisa é um parceiro do processo de investigação que compartilha com o pesquisador interpretações e significados sobre as experiências vividas, pois as histórias pessoais e profissionais do participante, relacionadas às ações ou atividades que realiza, trazem informações e indícios relevantes sobre o seu processo de formação ao longo do tempo.

Clandinin e Connelly (2000), apoiando-se nas idéias de John Dewey, escolheram os termos posição, continuidade e interação para dar suporte à pesquisa narrativa, e observam ainda que, quando o processo narrativo se inicia, a pesquisa narrativa "pulsa com movimentos para trás e para frente através do tempo e ao longo de um continuum de considerações sociais e pessoais" (p. 66). Assim, esses pesquisadores advogam que a educação e os estudos educacionais se dão em forma de experiência e criam o espaço tridimensional da pesquisa narrativa. A primeira dimensão seria a temporalidade, envolvendo passado, presente e futuro. A segunda corresponderia às interações pessoais e sociais. A terceira refere-se ao $l u$ gar ou cenário onde acontece a trama a ser narrada.

Essa metáfora de espaço tridimensional da pesquisa narrativa criada por Clandinin e Connelly apresenta alguma semelhança com a noção de chronotope ${ }^{6}$ de Bakhtin (1988), para quem o "tempo" e o "espaço" parecem essenciais para a compreensão do conhecimento advindo de uma experiência. $\mathrm{O}$ autor associa o termo chronotope "à ligação intrínseca das relações temporais e espaciais que são artisticamente expressas na literatura" (p. 84).

Assim, apoiados em Clandinin e Connelly e em Larrosa, mergulhamos na experiência que investigávamos e, junto com os protagonistas, fizemos parte do movimento vivido por eles, deixando-nos levar por seus caminhos. Nesse contexto de pesquisa, a narrativa passou a ser, de um lado, objeto de estudo, pois as histórias narradas tornaram-se alvo de nossas análises, e, de outro, método, pois também seria por meio da narrativa que exporíamos as análises, tornando públicos os significados da experiência investigada. Nesse sentido, foi necessário pensar sobre a experiência levando em conta três dimensões: temporal (passado - presente - futuro); pessoal-social; e posicional (lugar).

Nesse movimento instaurado, para melhor compreender os processos de vir a ser professor dos participantes, tendo a escrita discursiva como mediação da aprendizagem dos conceitos geométricos, fez-se necessário também nos compreender. Assim, revive-

\footnotetext{
${ }^{6}$ Termo cunhado por Bakhtin a partir da teoria da relativida-
} de de Einstein, para expressar a inseparabilidade entre tempo e espaço, sendo o tempo a quarta dimensão do espaço. 
mos na memória momentos do passado, relacionando-os com o momento vivido no presente e perspectivando possíveis futuros para os participantes. Acompanhamos a turma da disciplina Geometria Plana e Desenho Geométrico (GPDG), ministrada na licenciatura em matemática da UNICAMP no primeiro semestre de 2003, e, na impossibilidade de acompanhar a todos os alunos, selecionamos quatro para reviver e contar suas histórias em diferentes momentos do tempo, por meio de autobiografias (Abf), entrevistas ( $E_{1}$, $\mathrm{E}_{2}, \mathrm{E}_{3}$ ) e conversas presenciais e virtuais.

Para compreender o movimento de desenvolvimento pessoal e profissional dos protagonistas da pesquisa e construir suas narrativas de formação, muitas horas foram dedicadas à organização e leitura dos registros de campo produzidos ao longo do primeiro semestre de 2003 e também nos dois anos subseqüentes.

Assim, para cada protagonista, organizamos, primeiramente, um dossiê construído a partir de observações em classe, questionários, entrevistas, autobiografias, relatórios e registros escritos dos participantes, e e-mails (Eml). Após análise e interpretação desse material, numa perspectiva diacrônica, foi tecida a narrativa de formação de cada um, trazendo à tona aspectos importantes da presença da escrita na constituição pessoal e profissional dos mesmos. Entretanto, em virtude da limitação de espaço, apresentamos, neste artigo, apenas uma dessas narrativas.

\section{Fred Smith e seus caminhos de escrita e docência}

Fred, ao escrever sua autobiografia, conta que desde criança sentia atração pela matemática, o que influenciou sua opção pelo curso. O desejo de ser professor de matemática, entretanto, veio devagar, quase por acaso: "Não tive tantos impulsos para escolher essa profissão" (Eml/FS7 $)$. Ao iniciar a licenciatura, teve algumas reprovações e foi obrigado a mudar de turma. $\mathrm{Na}$ nova turma encontrou colegas interessados pela

\footnotetext{
${ }^{7}$ Trecho de e-mail enviado em 08 de agosto de 2005.
}

profissão docente: "Foi aí que eu comecei a ter contato com alunos que entraram no curso de matemática somente para serem professores, sem contar os que já lecionavam [...] e começou a passar pela minha cabeça a idéia de dar aula" (Abf/FS). ${ }^{8}$

Ao escrever sua história, Fred olha para si e para os outros, e percebe o momento e as razões que mudaram seu rumo. A interlocução com colegas motivados pela profissão docente, e o fato de alguns deles já estarem nela inseridos, trouxe-lhe uma nova perspectiva para seu futuro, sobretudo o desejo da docência. E assim, "após dois anos apenas me dedicando à universidade, achei que estava na hora de entrar realmente em sala de aula como professor" (Abf/FS).

Movido pela idéia de ser professor, "e aliado a uma vontade e a uma causa nobre", Fred buscou apoio e, "após um bom tempo de discussões, conversas com políticos, entrevistas em rádios e jornais...”, conseguiu, com mais alguns colegas, "montar um cursinho comunitário e gratuito para pessoas carentes. E o cursinho acabou sendo um sucesso (inclusive com vários aprovados) e adorei a experiência com os alunos" (Abf/FS).

Fred era preocupado com as causas sociais e, ao interagir com um colega que já lecionava, identificase com ele, mas acrescenta um outro sentido à atividade docente, um sentido social e político. Esse redimensionamento para ocupar seu lugar, acrescentando o que lhe faz sentido, nos remete a Bakhtin (2000), quando este faz alusão ao excedente de visão de cada um em relação ao outro:

Devo identificar-me com o outro e ver o mundo através de seu sistema de valores, tal como ele o vê; devo colocar-me em seu lugar, e depois, de volta ao meu lugar, completar seu horizonte com tudo que se descobre do lugar que ocupo, fora dele; devo emoldurá-lo, criar-lhe um ambiente que o acabe, mediante o excedente de minha visão, de meu saber, de meu desejo e de meu sentimento. (p. 45)

${ }^{8}$ Trecho da autobiografia produzida para a disciplina Prática de Ensino de Matemática e Estágio Supervisionado I - PEMES I - no primeiro semestre de 2004. 
A forma de Fred ver o mundo e seu compromisso político o mobilizaram a buscar, de um lado, apoio para o oferecimento de um cursinho destinado a alunos carentes e, de outro, aprimoramento profissional, optando pela realização do curso de geometria com a professora Sandra. Iniciou-o com muita expectativa e dúvida, pois era uma proposta pouco comum no contexto das disciplinas específicas.

As primeiras aulas na disciplina GPDG com a professora Sandra lhe causaram expectativa e ansiedade, talvez pela proposta pouco comum no contexto das disciplinas de matemática: "No começo, na primeira aula, a gente não tem noção. Então a gente fica imaginando, eu e os outros, achamos que ia ser bem difícil" $\left(\mathrm{E}_{1} / \mathrm{FS}^{9}\right)$.

Tempos depois, ao refletir sobre a experiência vivida, Fred redimensionou sua primeira impressão: "No final, a gente viu que foi exatamente o contrário. Foi uma das matérias mais fáceis em termos de nota. A idéia não era estar reprovando ninguém e tal. E foram muito legais as atividades" $\left(\mathrm{E}_{1} / \mathrm{FS}\right)$.

Contrapondo-se à facilidade relacionada à obtenção de nota, Fred destaca a dimensão compreensiva ${ }^{10}$ da geometria, que adquiriu com as atividades desenvolvidas:

[...] contribuíram desde a compreensão da matéria mesmo.

Era às vezes uma coisa que a gente sabia, mas não tinha

esse contato [...], várias coisas, [...] regrinhas, teoremas, a

gente sabia de cor porque tem que saber, mas a gente não

${ }^{9}$ Trecho da primeira entrevista concedida por FS (E $/$ /FS) em junho de 2003.

${ }^{10}$ Fiorentini e Costa (2002, p. 313) conceituam a formação compreensiva como aquela que "enfatiza a compreensão lógica, epistemológica, semiótica e histórica da matéria que ensina”. Esse domínio compreensivo da matéria "é fundamental para que o professor tenha autonomia intelectual para produzir o seu próprio currículo, constituindo-se efetivamente como mediador entre o conhecimento historicamente produzido e aquele - o escolar reelaborado e relevante socioculturalmente - a ser apropriado/construído pelos alunos". sabia muito bem da onde veio. Aí foi bem interessante as aulas nesse sentido. ( $\left.\mathrm{E}_{1} / \mathrm{FS}\right)$

Nesse contexto da disciplina, em que a compreensão ocupou um lugar de destaque, Fred reconhece o papel mediador da escrita no processo de produção de sentido sobre o que aprendia:

Acho que quando você tem que escrever um texto, aí é que você vê se está sabendo realmente. Porque você tem que explicar tudo certinho. Às vezes você sabe para você, mas não sabe como passar isso daí. Então eu acho que quando você está escrevendo um texto, facilita a sua compreensão. $\left(\mathrm{E}_{1} / \mathrm{FS}\right)$

Compartilhar com a turma ou interagir com colegas sobre as atividades (de laboratório ou do projeto) e as idéias veiculadas durante a disciplina foram práticas formativas para Fred:

A fala de um com o outro trazia muito beneficio, às vezes a Dóris ficava brava se a gente estava fazendo alguma coisa e tal, falando de outra coisa. Mas, é que eu acho fundamental que a gente deveria sempre ter um tempinho para conversar com os outros sobre a atividade, falar sobre a atividade. $\left(\mathrm{E}_{1} / \mathrm{FS}\right)$

Essa passagem lembra-nos o que diz Beatriz D’Ambrosio (2002) em “Conversas matemáticas", sobretudo quando, na interação com o outro, o pensamento de cada um recebe ajustes e modificações para adequar-se à construção das idéias surgidas no contexto interativo:

\footnotetext{
[...] no esforço para colocar suas idéias aos colegas, os alunos expõem seu conhecimento de forma pura e profunda. Percebe-se também que, no caso de uma conversa genuína, a construção de cada aluno participante é modificada durante a interação. (p. 19)
}

Fred reconhece que oralidade e escrita são meios importantes para expressar pensamentos e idéias, e o estilo inerente a cada modalidade parece fazer a dife- 
rença para a comunicabilidade. Percebe que nas várias esferas sociais em que transita, e no próprio curso de matemática, emergiram formas discursivas diversas que complementam a produção de significados. Reconhece principalmente que, ao explicar uma idéia a alguém que não possui domínio formal do assunto, a forma discursiva - textual ou oral - desponta como possibilidade de comunicação e entendimento:

Acho que são dois momentos que ajudam. A parte da escrita e a hora que você está falando para alguém também eu acho que é bem importante. Quando você passa para o papel e quando você vai tentar explicar para alguém, principalmente se alguém não viu aquilo lá. [...] faltou na aula. Então você vai ter que explicar. Já é totalmente diferente de você só mostrar e fazer a demonstração. Você colocar no papel explicando um texto assim, ou falando para a pessoa, já muda bastante. $\left(\mathrm{E}_{1} / \mathrm{FS}\right)$

A comunicação com o outro, nas aulas de matemática, em uma linguagem não apenas técnica e formal, foi considerada contributiva para sua formação, sobretudo a escrita de uma carta sobre uma demonstração do Teorema de Pitágoras, destinada a alguém com pouco ou nenhum domínio de matemática:

Ah! É isso que é legal! Porque aí você acaba fazendo um texto, que todo mundo entenda e falando do seu jeito, explicando a parte da matemática, só que do seu jeito, do jeito que você entendeu e você tenta explicar de uma maneira mais fácil para a pessoa. Você não pode simplesmente fazer o que a gente está acostumado, uma matemática pura, fazer demonstração... Isso devia ser aplicado com alunos, não só de Faculdade... no ensino médio também. $\left(\mathrm{E}_{1} / \mathrm{FS}\right)$

Na afirmação "explicando a parte da matemática, só que do seu jeito", Fred destaca os diferentes gêneros de discurso (Bakhtin, 2000) que são ou podem ser mobilizados nas diversas esferas da prática social para facilitar a compreensão entre as pessoas.

Fred revelou que a escrita, em sua vida escolar, sempre foi algo imposto e pouco prazeroso. Porém, as atividades desenvolvidas na disciplina GPDG mobilizaram suas reminiscências com a escrita, evocan- do uma experiência interessante ocorrida fora do ambiente escolar:

A única experiência que eu tive mais a ver com a escrita, porque eu quis, foi quando estávamos escrevendo uns episódios que aconteceram lá no bairro. Tem uma turma que estávamos vinte anos juntos e a gente começou tentar escrever a história sobre a turma. Foi bem legal! Eu adorei!

Aparentemente não tem nada a ver com a matemática... [Mas] quando você parava para pensar sobre o assunto você estava relembrando de coisas que normalmente você não lembrava. ( $\left.\mathrm{E}_{1} / \mathrm{FS}\right)$

Os acontecimentos recentemente vividos, que incluíram a escrita discursiva em forma de texto na disciplina GPDG, trouxeram a Fred outras lembranças que, narradas, produziram outros significados e relações que podem não ser imediatamente percebidos. Ao dizer "aparentemente não tem nada a ver com a matemática”, Fred parece já assumir que a escrita discursiva faz parte da matemática, tomando consciência dessa aproximação.

O envolvimento na disciplina Prática de Ensino e Estágio Supervisionado, no ano subseqüente àquele em que cursara GPDG, levou Fred a reconhecer que, apesar de sempre ter gostado de escrever, nos últimos tempos havia interrompido essa prática de escrita discursiva em forma de texto explicativo: "Eu tinha parado de escrever durante uns três anos. Eu não tinha escrito mais nada" $\left(\mathrm{E}_{2} / \mathrm{FS}^{11}\right)$. A consciência da retomada da escrita o fez notar que o processo de escrita provoca reflexões que reavivam idéias que parecem adormecidas. Além disso, a prática de escrita ressaltou para Fred a importância de dar voz e ouvidos aos alunos, registrando por escrito o que eles dizem:

$[\ldots]$ a retomada da escrita aconteceu na aula da Sandra. E
uma coisa muito interessante que aconteceu foi com a ma-
téria com o Dario. Que ele pediu para eu fazer um diário
reflexivo e eu nunca tive a idéia de fazer alguma coisa des-

${ }^{11}$ Trecho da segunda entrevista $-\mathrm{E}_{2} / \mathrm{FS}$ - realizada em novembro de 2004. 
se tipo. Então o que acontecia: eu assistia as aulas no dia da semana, refletia sobre aquelas aulas e nisso eu fui percebendo que eu tinha todas as idéias na cabeça só que quando você coloca no papel você põe de uma forma organizada e consegue refletir sobre o que você escreveu e então você consegue ter novas idéias a partir daquilo lá e eu achei muito interessante isso. A gente vai percebendo coisas que na hora você não percebe. As coisas que os alunos falam e esse tipo de coisa que passa despercebido... $\left(\mathrm{E}_{2} / \mathrm{FS}\right)$

Fred, ao escrever sobre a prática de ensino de matemática, percebeu, de um lado, que a escrita promove a tomada de consciência de seus conhecimentos e crenças acerca do ensino e da aprendizagem da matemática, desencadeando, assim, processos metacognitivos: "Você consegue refletir sobre o que você escreveu"; em contrapartida, notou também que o registro escrito permite a produção de outros sentidos sobre a prática educativa, e que não são percebidos no momento da ação: "Você consegue ter novas idéias a partir daquilo lá [...]. A gente vai percebendo coisas que na hora você não percebe".

Após realizar a disciplina GPDG e o estágio, Fred foi assumindo cada vez mais intensamente a docência, de modo que seu tempo foi quase todo ocupado com suas responsabilidades de professor e estudante. Por isso, foram poucos os nossos contatos presenciais, além das duas entrevistas agendadas. Porém, os contatos virtuais, via correio eletrônico, totalizaram 61 até meados de agosto de 2005.

Identificando-se progressivamente com a sua imagem de professor, Fred envaidece-se com algumas conquistas que parecem estimular sua confiança para atuar na profissão:

Participei de um processo seletivo para professores na melhor escola de Campinas, [...] e que foi composto de duas fases: prova e aula teste. Fiquei muito contente, pois muita gente daqui do IMECC [Instituto de Matemática, Estatística e Computação Científica] estava participando e eu fiquei em primeiro lugar... $(\mathrm{Eml} / \mathrm{FS})^{12}$

\footnotetext{
${ }^{12}$ Trecho de e-mail enviado em 19 de novembro de 2003.
}

O sucesso de Fred nesse processo seletivo para professores deve-se, em grande parte, às oportunidades de interação ao longo de sua trajetória de formação. Avalia, entretanto, que falta ao futuro professor conhecer mais a realidade escolar, sobretudo suas necessidades didático-pedagógicas: "A gente começa a dar aula sem antes ter uma idéia do que as escolas querem do professor". Além disso, pondera que a vivência do modelo tradicional de ensino privilegiado nas disciplinas de matemática da licenciatura mais prejudica que ajuda a futura prática docente:

O pessoal quer dar aula para o ensino médio como eles vêem a aula do IMECC, por exemplo. A aula é tradicionalíssima... Você vai à lousa e escreve mal escrito, mal organizado na lousa. Coloca a definição, demonstra tudo e não está nem aí com o aluno. ( $\left.\mathrm{E}_{2} / \mathrm{FS}\right)$

A multiplicidade de aspectos que compõem a constituição do professor tende a ser enriquecida à medida que se estabelecem interações diversas com os outros e consigo mesmo, de modo que se intensifique o potencial reflexivo e crítico dos envolvidos no processo. A mediação envolvendo a escrita do professor e do aluno ajuda a promover o diálogo e as interações em sala de aula, bem como o processo de produção e negociação de significados. De fato, nas disciplinas em que a escrita se fez presente, percebeu-se que o professor necessariamente ouve seu aluno pela leitura de sua escrita, e este, por sua vez, ouve o professor quando propõe e dá retorno às tarefas realizadas, em especial quando a dinâmica desse diálogo extrapola os limites herméticos da linguagem formal.

Aos poucos, a idéia de aliar a escrita de textos ao ensino de matemática foi-se fortalecendo no pensamento de Fred e, ao referir-se ao futuro, revela um sonho: "Falando já em planos, eu penso em escrever um livro de Matemática Com-Textos" (por meio de textos). A interlocução com os alunos e as experiências que Fred possuía até então, como professor e como aluno, levaram-no a perceber a necessidade de incluir mais textos explicativos nos livros de matemática: 
Eu descobri com os alunos que eles têm a necessidade disso daí, e eles gostariam. Porque na verdade a apostila de matemática e o livro de matemática não explicam nada. Colocam definição, fórmulas e fórmulas...

E eu estava com a idéia de escrever alguma coisa através de textos.

Então eu fiquei já este ano inteiro conversando com os alunos para ver o que eles acham de cada matéria. Como é que faz para explicar melhor... e tal. $\left(\mathrm{E}_{2} / \mathrm{FS}\right)$

As interações estabelecidas ao longo de sua trajetória de formação vêm contribuindo para despertar novas idéias sobre o ensino e a aprendizagem da matemática. Dentre outros espaços ou momentos de formação, Fred destaca "ter trabalhado com geometria e com o computador". Vivenciar na formação a inserção de tecnologia e outras mediações de ensino de matemática tende a oferecer ao futuro professor maior credibilidade e confiança no uso desses recursos:

[...] a gente percebeu que se aprende muito mais trabalhar geometria com o computador. Você trabalhar qualquer tópico de matemática com o computador. Outra coisa: trabalhar qualquer tópico de matemática, não necessariamente com o computador, mas com outros... Por exemplo: calculadora, calculadora gráfica, alguma coisa desse tipo. Trabalhar qualquer conteúdo de matemática através de resolução de problemas, aulas investigativas e através da reflexão mesmo e reflexão por escrito. $\left(\mathrm{E}_{2} \mathrm{FS}\right)$

Dando continuidade à sua graduação, Fred participou de outras disciplinas, entre elas Prática de Ensino de Matemática e Estágio Supervisionado (PEMES), em que a prática da escrita também fora enfatizada. Embora, em ambas as disciplinas, a reflexão apresente-se com muita proeminência, percebeu uma diferença em relação ao papel da escrita:

Acho que a atividade da reflexão é uma coisa muito importante e se não fosse a matéria da Sandra a gente estaria na matéria do Dario, a gente teria o contato com essa reflexão, mas não iria estar entendendo o porquê.

Enquanto uma escrita se voltava para o ato de aprender e tratar a matemática em si (GPDG), a outra
(PEMES) priorizava a prática escolar do ensino da matemática e as relações didático-pedagógicas:

A gente ia fazer aquilo lá de uma forma... até poderia entender. Só que a gente ia pensar o seguinte. A gente está fazendo um texto refletindo sobre coisas diferentes do conteúdo matemático. Sobre relacionamento, por exemplo, ou escola com professor e... essas coisas. Só que lá com a Sandra a gente viu que os tópicos de matemática, a gente fazendo uma reflexão por escrito, a gente consegue entender mais e transmitir melhor.

A gente consegue ver outras áreas. Mas no conteúdo de matemática a gente percebeu que isso funciona. $\left(\mathrm{E}_{2} \mathrm{FS}\right)$

Quando diz: "a gente teria o contacto com essa reflexão, mas não iria estar entendendo", Fred parece admitir que, embora reconheça a importância da reflexão escrita sobre a prática pedagógica em matemática, sente que a reflexão escrita sobre os conteúdos matemáticos, na formação inicial, também é essencial para a formação do professor, pois estabelece outras relações fundamentais com o conteúdo e pode contribuir para que o futuro professor também venha a implementar a prática da escrita com seus alunos, quando estão aprendendo matemática na escola. Em suma, essas duas formas de refletir por escrito foram importantes para sua formação, pois uma complementava a outra.

O envolvimento da escrita discursiva nas disciplinas de PEMES I e II abriu espaço para a reflexão sobre a prática da docência e, em especial, sobre o professor de matemática, minimizando um dos problemas, na formação de professores, relacionados à dicotomia entre teoria e prática.

Em síntese, esse pequeno trailer da história da formação de Fred traz imagens de um jovem muito comunicativo que, embora não almejasse como primeira opção a carreira docente, foi levado a mudar de rumo pelas interações estabelecidas - com colegas, professores e a escrita - ao longo de seu caminho, passando a reconhecer-se e a identificar-se como professor de matemática que reflete e almeja contribuir para a transformação social. Na sua trajetória de formação de professor de matemática identificou e va- 
lorizou, ora de modo implícito, ora explícito, os diferentes papéis que a escrita pode assumir, tanto no processo de educação matemática de seus alunos quanto em seu próprio desenvolvimento profissional.

\section{Remates na tecedura de histórias de formação}

A inserção da escrita discursiva em diferentes momentos da formação e o lembrar e narrar por escrito (ou oralmente) histórias da trajetória formativa experienciada pelos protagonistas da pesquisa contribuíram para que se desenvolvessem profissionalmente, tornando-se agenciadores de suas reflexões e autores de suas imagens e conceitos. Além disso, pôdese evidenciar que a experiência discente com a escrita discursiva sobre a matemática, na formação inicial, influenciou a prática futura dos professores, pois estes passaram também a explorá-la didático-pedagogicamente com seus alunos.

A organização, por escrito, dos pensamentos e das idéias permitia aos (futuros) professores que seus conhecimentos docentes, às vezes ditos como tácitos, fossem identificados, problematizados e (re)significados.

A busca de um estilo mais apropriado para expressar-se de forma compreensível, nos textos escritos, colocou em evidência diferentes gêneros discursivos (carta, diário, narrativa, desenhos...). Isso ajudou a promover a comunicação, a compreensão e o entendimento mútuo de alunos e professor. Esses gêneros deram aos estudantes visibilidade, para si e para os outros, ao que pensam e sentem quando aprendem matemática, ajudando a orientar as ações do formador.

A liberdade de pensamento instaurada pela prática da escrita permitiu e propiciou que muitos dos protagonistas (re)significassem seu modo de atuar e organizar o trabalho pedagógico, empenhando-se para que a liberdade de expressão no ambiente de ensinoaprendizagem ocorresse em suas aulas. As narrativas de formação oportunizaram, entre outras contribuições da inserção da escrita no contexto de formação de professores de matemática, o incentivo ao desenvolvimento da capacidade de análise durante a inves- tigação, elucidando serem a escrita e a análise elementos indissociáveis.

Entretanto, ainda sabemos pouco sobre o papel e a contribuição da escrita discursiva e reflexiva nas disciplinas de formação matemática do futuro professor. São poucos os formadores que ministram essas disciplinas tendo como mediação a leitura e a escrita discursiva. E mais raro ainda são aqueles que tomam essa prática como objeto de estudo. Esperamos que esta pesquisa sirva de estímulo para ampliar o número de professores - tanto no ensino superior quanto no ensino básico - interessados em experienciar e investigar essa prática nas aulas de matemática.

\section{Referências bibliográficas}

BAKHTIN, Mikhail. Marxismo e filosofia da linguagem: problemas fundamentais do método sociológico na ciência da linguagem. São Paulo: Hucitec, 1986.

The dialogic imagination. 6. ed. Austin: University of Texas Press, 1988.

. Estética da criação verbal. Trad. do francês Maria

Ermantina Galvão G. Pereira. 3. ed. São Paulo: Martins Fontes, 2000. BOGDAN, Robert; BIKLEN, Sari Knopp. Investigação qualitativa em educação. Portugal: Porto Editora, 1994.

BRITTO, Luiz Percival Leme. Contra o consenso: cultura, escrita, educação e participação. Campinas: Mercado de Letras, 2003. BRUNER, Jerome. Realidade mental, mundos possiveis. Porto Alegre: Artes Médicas, 1997.

CLANDININ, Jean Dorothy; CONNELLY, Michael. Narrative inquiry: experience and story in qualitative research. San Francisco: Jossey-Bass Publishers, 2000.

D’AMBROSIO, Beatriz Silva. Conversas matemáticas: metodologia de pesquisa ou prática profissional: In: ENCONTRO BRASILEIRO DE ESTUDANTES DE PÓS-GRADUAÇÃO EM EDUCAÇÃO MATEMÁTICA (EBRAPEM), 6., 2002, Campinas. Anais... Campinas: Graf FE, 2002. p. 18-20.

FIORENTINI Dario; COSTA, Gilvan Luiz Machado. Enfoques da formação docente e imagens associadas de professor de Matemática. Contrapontos - Revista de Educação da Universidade do Vale do Itajaí, Itajaí, ano 2, n. 6, p. 309-324, set./dez. 2002.

FREITAS, Maria Teresa Menezes. Estágio curricular em matemática na perspectiva de extensão universitária: estudo de uma 
experiência na UFU. 2000. 165f. Dissertação (Mestrado em Educação) - Faculdade de Educação, Universidade Federal de Uberlândia, Uberlândia, 2000.

A escrita no processo de formação contínua do professor de matemática. 2006. 300f. Tese (Doutorado em Educação Matemática) - Faculdade de Educação, Universidade Estadual de Campinas, Campinas, 2006.

KRAMER, Sônia. Escrita, experiência e formação - múltiplas possibilidades de criação de escrita. In: CANDAU, Vera Maria (Org.). Linguagens, espaços e tempos no ensinar e aprender. Rio de Janeiro: DP\&A, 2000. p. 105-121.

LARROSA, Jorge. Notas sobre a experiência e o saber da experiência. Revista Brasileira de Educação, n. 19, p. 20-28, jan./abr. 2002. OLIVEIRA, Marta Kohl. Letramento, cultura e modalidades de pensamento. In: KLEIMAN, Angela B. (Org.). Os significados do letramento: uma nova perspectiva sobre a prática social da escrita. Campinas: Mercado de Letras, 1995. p. 147-160.

POWELL, Arthur Belford. Captando, examinando e reagindo ao pensamento matemático. Boletim 39, Rio de Janeiro: GEPEM, p. $73-84$, set. 2001 .

.; BAIRRAL, Marcelo. A escrita e o pensamento matemático: interações e potencialidades. Campinas: Papirus, 2006.

MARIA TERESA MENEZES FREITAS, doutora em educação matemática pela Faculdade de Educação da Universidade Estadual de Campinas (UNICAMP), é atualmente docente da Faculdade de Matemática da Universidade Federal de Uberlândia (UFU). Envolvida com projetos de extensão com foco no desenvolvimento profissional do professor que ensina matemática, participou da implantação do Laboratório de Ensino de Matemática nessa universidade, no início da década de 1990, tendo sido coordenadora dele por mais de dez anos. Atualmente equilibra suas atividades de docência na Faculdade de Matemática com cargos de coordenação do Núcleo de Educação Matemática e a coordenação de estágio do curso de licenciatura em matemática da UFU. Desde 2002, desenvolve também estudos e pesquisas com o Grupo de Estudo e Pesquisa sobre Formação de Professores que Ensinam Matemática (GEPFPM), da UNICAMP. Publicações relevantes: com Dario Fiorentini: "Comunicação e formação: o papel da escrita na formação inicial de professores de Matemática" (In: AYMERICH, Vives (Ed.). Matemáticas para el siglo XXI. (Castelló de la Plana: Publicacions de la Universitat Jaume I, D.L., 2006, p. 235-244); com colegas do grupo de pesquisa (GEPFPM): "O desafio de ser professor de Matemática hoje no Brasil" (In:
FIORENTINI, Dario; NACARATO, Adair Mendes (Orgs.). Cultura, formação e desenvolvimento profissional de professores que ensinam matemática. São Paulo: Musa, 2005, p. 89-105); com Diana Jaramillo e Adair Mendes Nacarato, "Diversos caminhos de formação: apontando para outra cultura profissional do professor que ensina Matemática" (In: NACARATO, Adair Mendes; LOPES, Celi Aparecida Espasandin (Orgs.). Escritas e leituras na educação matemática, Belo Horizonte: Autêntica, 2005, p. 163190). Pesquisa em desenvolvimento, apoiada pelo Programa Especial de Pesquisa da UFU (PEP-UFU): “A utilização de um ambiente virtual como recurso didático-pedagógico complementar em disciplina presencial no Curso de Matemática". E-mail: mtmfreitas@gmail.com; mtmf@ufu.br

DARIO FIORENTINI, doutor em educação pela Universidade Estadual de Campinas (UNICAMP), atualmente é docente pesquisador da área de educação matemática e do Programa de Pós-Graduação em Educação da Faculdade de Educação da mesma universidade. Publicou mais de 50 trabalhos em periódicos e capítulos de livros, dentre os quais destaca: "Pesquisar práticas colaborativas ou pesquisar colaborativamente?" (In: BORBA, Marcelo de Carvalho; ARAÚJO, Jussara de Loiola (Orgs.). Pesquisa qualitativa em educação matemática, Belo Horizonte: Autêntica, 2004, p. 47-76); em co-autoria com outros colegas: "Formação de professores que ensinam Matemática: um balanço de 25 anos da pesquisa brasileira" (Educação em Revista, Belo Horizonte: UFMG, n. 36, p. 137-160, 2002); autor ou organizador de sete livros, dentre os quais se destacam: com LORENZATO, Sergio: Investigação em educação matemática: percursos teóricos e metodológicos (Campinas: Autores Associados, 2006); com NACARATO, Adair Mendes: Cultura, formação e desenvolvimento profissional de professores que ensinam Matemática (São Paulo: Musa Editora, 2005); com GERALDI, Wanderley; PEREIRA, Elisabete Monteiro de Aguiar: Cartografias do trabalho docente (Campinas: Mercado de Letras, 1998). Coordena o Grupo de Pesquisa Prática Pedagógica em Matemática (PRAPEM) e de seus subgrupos Grupo de Estudo e Pesquisa sobre Formação de Professores de Matemática (GEPFPM) e Grupo de Sábado (GdS). Projeto atual de pesquisa: "Inter-relações entre formação docente e desenvolvimento curricular".E-mail: dariof@unicamp.br

Recebido em outubro de 2006 Aprovado em agosto de 2007 
Maria Teresa Menezes Freitas e

Dario Fiorentini

Desafios e potencialidades da escrita na formação docente em matemática Esse estudo teve como objetivo investigar como futuros professores da licenciatura respondem à experiência de uma disciplina de formação matemática que privilegia o registro escrito discursivo e reflexivo. A pesquisa foi orientada pelas questões: que contribuições a inserção de diferentes formas de comunicação, especialmente a escrita, em uma disciplina de geometria, traz à formação e ao desenvolvimento profissional do futuro professor? Como acontece, nesse processo, a constituição da identidade profisssional? A investigação narrativa foi eleita como método de pesquisa, contando com registros etnográficos, entrevistas, relatórios e mensagens pela internet. Subsidiada teoricamente pelos estudos histórico-culturais, a aproximação do movimento de formação dos alunos/ professores iniciou-se em 2003, prolongando-se até 2005. O texto traz uma das narrativas de formação, evidenciando aspectos importantes da presença da escrita na constituição pessoal e profissional do professor.

Palavras-chave: formação de professores de matemática; narrativas de formação; escrita na formação docente

\section{Challenges and potentialities of} writing in the professional development of mathematics teachers

The purpose of this study was to obtain relevant insights into how students on a course for future mathematics teachers react to the experience of participating in a mathematics discipline which emphasizes the written register of thoughts and ideas occurring during the learning process.

The guiding questions in the research

were: what are the significant

contributions of the presence of

different forms of communication (with special emphasis on written

communication) in a course of geometry with regard to the training and professional development of the future mathematics teacher? How is a professional identity constituted in this process? Narrative inquiry was chosen as the research method, based upon ethnographic register, interviews, written reports and e-mails. The research, based on historical and cultural studies, was initiated in 2003 and lasted until 2005. This text presents one of the written training narratives highlighting important aspects of the presence of writing in the personal and professional preparation of the teacher.

Key words: training of mathematics teachers; training narratives; writing in teacher training

\section{Desafíos y potencialidades de la} escritura en la formación de docentes en matemáticas

El objetivo de este estudio es investigar cómo los futuros profesores de licenciatura responden a la experiencia de una disciplina de formación matemática que privilegia el registro escrito, discursivo y reflexivo. $\mathrm{La}$ investigación fue dirigida por las preguntas: ¿qué contribuciones trae la inserción de diversas formas de comunicación, especialmente la escrita, en una disciplina de geometría a la formación y al desarrollo profesional del futuro profesor? ¿Cómo sucede, en este proceso, la constitución de la identidad profesional? La búsqueda narrativa fue elegida como método de investigación, contando con registros etnográficos, entrevistas, informes y emails. Subvencionada teóricamente por los estudios histórico-culturales, la aproximación del movimiento de la formación de los alumnos/profesores comenzó en 2003, prolongándose hasta 2005. El texto trae una de las narrativas de la formación, evidenciando los aspectos importantes de la presencia de la escritura en la constitución personal y profesional del profesor.

Palabras claves: formación de profesores de matemáticas; narrativas de la formación; escritura en la formación docente 